\title{
Comunicação \\ Tolerância do maxixeiro, cultivado em vasos, à salinidade da água de irrigação
}

\author{
Francisco de Assis de Oliveira ${ }^{1}$, Kayeshella Samantha de Oliveira Pinto ${ }^{2}$, \\ Francisco Mardones Sérvulo Bezerra², Luan Alves de Lima², Antônio Lucieudo Gonçalves Cavancante ${ }^{3}$, \\ Mychelle Karla Teixeira de Oliveira ${ }^{4}$, José Francismar de Medeiros ${ }^{5}$
}

\section{RESUMO}

O maxixeiro é uma cultura de grande importância nas regiões Norte e Nordeste do Brasil e a sua produção é oriunda, predominantemente, de plantas espontâneas. Em razão disso, são poucas as pesquisas sobre a cultura, principalmente no tocante ao efeito da salinidade. Este trabalho foi desenvolvido na Universidade Federal Rural do Semiárido (UFERSA), em Mossoró, RN, com o objetivo de avaliar o efeito de diferentes níveis de salinidade da água de irrigação sobre o desenvolvimento e o rendimento do maxixeiro. Utilizou-se o delineamento experimental inteiramente ao acaso, com quatro tratamentos (níveis de salinidade da água de irrigação: $\mathrm{S}_{1}-0,5 ; \mathrm{S}_{2}-2,0 ; \mathrm{S}_{3}-3,5$ e $\mathrm{S}_{4}-5,0$ dS m $\mathrm{m}^{-1}$ ). Foram realizadas cinco colheitas de frutos e, ao final do experimento, as plantas foram coletadas e foram analisadas as principais variáveis de desenvolvimento e de rendimento: comprimento do ramo principal, diâmetro do caule, número de folhas, área foliar, massas de matéria seca de folhas, hastes, frutos e total, número de frutos, massa média de frutos e produção. O maxixeiro apresentou-se como cultura sensível à salinidade. Houve respostas significativas para todas as variáveis avaliadas, as quais apresentaram reduções em seus valores, com o aumento da salinidade.

Palavras-chave: Cucumis anguria L., estresse salino, tolerância à salinidade.

\section{ABSTRACT}

\section{Tolerance of potted gherkin to salinity of irrigation water}

Gherkin (Cucumis anguria) is an important crop in the North and Northeast regions of Brazil, and its production is predominantly from spontaneously growing plants. For this reason, little research is done on the crop, especially regarding the effect of salinity. This study was conducted at the Federal Rural University of the Semiarid (UFERSA) in Mossoró, RN, to evaluate the effect of different salinity levels of irrigation water on the development and yield of gherkin. The experiment was arranged in a completely randomized design, with four treatments (salinity levels of irrigation water: $\mathrm{S}_{1}-0.5, \mathrm{~S}_{2}-2.0, \mathrm{~S}_{3}-3.5$ and $\mathrm{S}_{4}-5.0 \mathrm{dS} \mathrm{m} \mathrm{m}^{-1}$ ). There were five harvests of fruits and at the end of the experiment the plants were collected and analyzed for major development parameters and yield. We evaluated the following variables: length of the main branch, stem diameter, number of leaves, leaf area, dry mass of leaves, stems, fruits and total fruit number, average fruit weight and yield. The results showed that gherkin is sensitive to salinity. Significant responses were found for all variables that reduced with increasing salinity.

Key words: Cucumis anguria L., saline stress, salt tolerance.

\footnotetext{
Recebido para publicação em 04/03/2013 e aprovado em 17/06/2013.

'Engenheiro-Agrônomo, Doutor. Departamento de Ciências Ambientais e Tecnológicas, Universidade Federal Rural do Semi-Árido, Avenida Francisco Mota, 572, Bairro Costa e Silva, 59625-90, Mossoró, Rio Grande do Norte, Brasil. thikaoamigao@ufersa.edu.br (autor para correspondência).

${ }^{2}$ Graduandos em Agronomia. Universidade Federal Rural do Semi-Árido, Avenida Francisco Mota, 572, Bairro Costa e Silva, 59625-90, Mossoró, Rio Grande do Norte, Brasil. k_shella@hotmail.com; mardonnestec@hotmail; luanefa2@yahoo.com.br com

${ }^{3}$ Graduando em Engenharia Florestal. Universidade Federal Rural do Semi-Árido, Avenida Francisco Mota, 572, Bairro Costa e Silva, 59625-90, Mossoró, Rio Grande do Norte, Brasil. lucieudotecnicoagropecuaria@yahoo.com.br

${ }^{4}$ Engenheira-Agrônoma, Mestre. Departamento de Ciências Ambientais e Tecnológicas, Universidade Federal Rural do Semi-Árido, Avenida Francisco Mota, 572, Bairro Costa e Silva, 59625-90, Mossoró, Rio Grande do Norte, Brasil. mkto10@ hotmail.com

${ }^{5}$ Engenheiro-Agrônomo, Doutor. Departamento de Ciências Ambientais e Tecnológicas, Universidade Federal Rural do Semi-Árido, Avenida Francisco Mota, 572, Bairro Costa e Silva, 59625-90, Mossoró, Rio Grande do Norte, Brasil. jfmedeir@ufersa.edu.br (Pesquisador CNPq).
} 


\section{INTRODUÇÃO}

O maxixeiro (Cucumis anguria L.) é uma cultura de grande importância nas regiões Norte e Nordeste do Brasil. No entanto, a maior parte da produção desta hortaliça é obtida sem o uso de tecnologias adequadas. Os frutos de maxixe crus são ricos em nutrientes e sais minerais (NEPA, 2011), apresentando, ainda, propriedades medicinais, como ação emoliente, anti-helmíntica, anti-hemorroidal, antiemética e laxativa. Por ser rico em zinco, evita doenças na próstata, auxilia na redução do colesterol e na cicatrização de ferimentos internos e externos (Brasil, 2004).

No entanto, de acordo com dados do IBGE, o consumo de maxixe, na média nacional, ainda é muito baixo, com aquisição per capita em torno de $0,067 \mathrm{~kg} \mathrm{ano}^{-1}$, sendo os maiores índices de aquisição nas regiões Norte e Nordeste, com 0,172 e 0,130 kg ano ${ }^{-1}$ (IBGE, 2012). O baixo consumo de maxixe pode estar vinculado, entre outros fatores, ao reduzido período de vida pós-colheita, pois os frutos deterioram-se com facilidade, por causa de suas características fisiológicas. Entretanto, seus frutos podem ser processados na forma de conservas, apresentando boa aceitação pelos consumidores, maior vida de prateleira, elevado rendimento e baixo custo de produção, tornando-o produto comercializável durante todo o ano e com preço acessível (Nascimento et al., 2011).

Grande parte da produção dessa hortaliça é proveniente de plantas espontâneas, que nascem em áreas cultivadas com outras espécies, como o feijão e o milho, de forma que não são realizadas práticas culturais específicas para o maxixeiro.

A irrigação é uma das principais tecnologias capazes de trazer resultados satisfatórios ao desenvolvimento, rendimento e qualidade dos produtos agrícolas. No entanto, além da quantidade de água disponível para as plantas, outro fator de fundamental importância está relacionado com a qualidade da água, principalmente quanto à concentração de sais dissolvidos.

A inibição do crescimento das plantas sob salinidade ocorre por duas razões, a primeira deve-se ao efeito osmótico provocado pela salinidade, que reduz a absorção de água, e, a segunda, ao efeito específico ou ao seu excesso dos íons que entram no fluxo de transpiração e, eventualmente, causam injúrias nas folhas, reduzindo o crescimento ou influenciando negativamente na absorção de elementos essenciais (Munns, 2005).

Vários estudos já foram desenvolvidos para avaliar o efeito da salinidade do solo ou da água de irrigação sobre outras culturas de interesse agronômico, sendo, na maioria dos casos, encontrados resultados que demonstram efeito deletério da salinidade sobre o crescimento e o rendimento das plantas, a exemplo de cucurbitáceas, como o meloeiro (Dias et al., 2010; Medeiros et al., 2012), pepino
(Medeiros et al., 2009; Santana et al., 2010), abóbora (Carmo et al., 2011) e abobrinha (Strassburger et al., 2011).

No entanto, com relação à cultura do maxixeiro, especificamente, são poucos os estudos desenvolvidos (Góis et al., 2008; Oliveira et al., 2012). Essas publicações avaliaram o efeito da salinidade apenas sobre as fases de germinação e de desenvolvimento inicial de plântulas. Diante do exposto, este trabalho foi desenvolvido com o objetivo de avaliar o efeito de níveis de salinidade sobre o desenvolvimento do maxixeiro.

\section{MATERIAL E MÉTODOS}

O experimento foi conduzido de 20 de fevereiro a 25 de junho de 2012, no Departamento de Ciências Ambientais e Tecnológicas da Universidade Federal Rural do Semiárido - UFERSA, Mossoró, RN, Brasil, localizada nas coordenadas geográficas de $5^{\circ} 11^{\prime} \mathrm{S}$ e $37^{\circ} 20^{\prime} \mathrm{O}$, em altitude média de 18 m. O clima da região, na classificação de Köppen, é do tipo BSwh' (quente e seco), com precipitação pluviométrica bastante irregular, média anual de $673,9 \mathrm{~mm}$; temperatura de $27{ }^{\circ} \mathrm{C}$ e umidade relativa do ar média de 68,9\% (Carmo Filho \& Oliveira, 1995).

O delineamento experimental utilizado foi inteiramente ao acaso, com quatro tratamentos e seis repetições. Os tratamentos foram constituídos por quatro níveis de salinidade da água de irrigação $\left(\mathrm{S}_{1}-0,5 ; \mathrm{S}_{2}-2,0 ; \mathrm{S}_{3}-3,5\right.$ e $\mathrm{S}_{4}-$ $5,0 \mathrm{dS} \mathrm{m}^{-1}$ ) e a unidade experimental representada por um vaso plástico com capacidade para $12 \mathrm{~L}$, com uma planta em cada vaso.

Os diferentes níveis de salinidade foram obtidos pela dissolução de cloreto de sódio $(\mathrm{NaCl})$, em água do sistema de abastecimento do campus da UFERSA $\left(\mathrm{S}_{1}\right)$, ajustando-se com condutivímetro de bancada, com correção automática de temperatura. A água utilizada para representar o nível de salinidade de $0,5 \mathrm{dS} \mathrm{m}^{-1}$ e na obtenção dos demais níveis de salinidades, apresentou as seguintes características químicas: $\mathrm{pH}=8,30 ; \mathrm{CE}=0,50 \mathrm{dS} \mathrm{m}^{-1}$; $\mathrm{Ca}^{2+}=3,10 ; \mathrm{Mg}^{2+}=1,10 ; \mathrm{K}^{+}=0,30 ; \mathrm{Na}^{+}=2,30 ; \mathrm{Cl}^{-}=1,80 ;$ $\mathrm{HCO}_{3}^{-}=3,00 ; \mathrm{CO}_{3}{ }^{2-}=0,20\left(\mathrm{mmol}_{\mathrm{c}} \mathrm{L}^{-1}\right)$.

O solo utilizado foi um Latossolo Vermelho-Amarelo argissólico franco-arenoso, coletado na camada de 0-30 $\mathrm{m}$ de profundidade, em área não cultivada localizada no Campus da UFERSA. O material coletado foi secado ao ar e peneirado em malha de 2,0 $\mathrm{mm}$. Antes do acomodamento do solo nos vasos, foi retirada uma subamostra, para as análises físico-químicas (Embrapa, 1997), cujos resultados são apresentados na Tabela 1 .

No preenchimento dos vasos, foram colocados $10 \mathrm{dm}^{3}$, deixando-se cerca de $2 \mathrm{~cm}$ entre a superfície do solo e a borda superior do vaso, para facilitar a irrigação, buscando-se evitar possível transbordamento da água durante as irrigações, que foram realizadas manualmente, utilizando-se proveta graduada $(500 \mathrm{~mL})$. 
O material de solo foi acondicionado em cada vaso de forma que, após o término do enchimento, fosse obtida densidade semelhante àquela obtida na análise física (Tabela 1). Os vasos foram distribuídos a céu aberto, no espaçamento de $1,5 \times 0,5 \mathrm{~m}$, resultando numa densidade equivalente a 13.333 plantas por hectare. Durante o período experimental não ocorreram precipitações pluviométricas significativas, que pudessem mascarar o efeito dos tratamentos.

Após o acondicionamento do solo nos vasos, retiraram-se cinco vasos para determinação da capacidade de retenção de água, seguindo o método proposto por Casaroli \& Jong Van Lier (2008), os quais afirmam que a máxima capacidade de retenção de umidade de uma amostra de solo é referente à umidade da amostra quando se verifica o fim da drenagem.

Após o teste foi constatado, para a média dos cinco vasos, que o solo apresentou capacidade de retenção de água (CRA) de aproximadamente $0,15 \mathrm{~kg} \mathrm{~kg}^{-1}$. Dessa forma, considerando-se o volume de $10 \mathrm{dm}^{3}$ de solo, com densidade aparente de $1,53 \mathrm{~g} \mathrm{dm}^{3}$, foram necessários, aproximadamente, 2,3 litros de água em cada vaso.

Antes da semeadura, realizou-se adubação com N, $\mathrm{P}_{2} \mathrm{O}_{5}$ e $\mathrm{K}_{2} \mathrm{O}$, aplicando-se ao solo de cada vaso 100; 200 e 100 $\mathrm{mg} \mathrm{dm}{ }^{-3}$ de ureia, para fornecimento de $\mathrm{N}$, fosfatomonoamônico, para o fornecimento de $\mathrm{P}_{2} \mathrm{O}_{5}$ e de $\mathrm{N}$ e cloreto de potássio, para o de $\mathrm{K}_{2} \mathrm{O}$, respectivamente. Os fertilizantes foram diluídos em água, aplicando-se, a cada vaso, volume suficiente para elevar o teor de água do solo até a umidade correspondente à sua máxima capacidade de retenção de água. Não foi realizada a calagem, em virtude de o solo apresentar $\mathrm{pH}$ próximo ao da faixa adequada para a cultura, que é de 5,5 a 6,5 (Modolo \& Costa, 2003).

Além da adubação antes da semeadura, foram realizadas duas adubações de cobertura, aos 30 e 60 dias após a semeadura, aplicando-se cerca de 2,6 e 1,8 g por planta de $\mathrm{Ne} \mathrm{K}_{2} \mathrm{O}$, equivalente a $70 \mathrm{~kg} \mathrm{ha}^{-1}$ de $\mathrm{N}$ e $50 \mathrm{~kg} \mathrm{ha}^{-1} \mathrm{de}_{2} \mathrm{O}$, respectivamente, em cada adubação (Oliveira et al., 2008), utilizando-se ureia, como fonte de N, e cloreto de potás- sio, como fonte de $\mathrm{K}_{2} \mathrm{O}$. A fim de facilitar a aplicação, em virtude da pequena quantidade, os fertilizantes foram aplicados na forma de solução, semelhantemente à adubação de fundação.

Quinzenalmente, eram realizadas pulverizações com micronutrientes, utilizando-se solução de Quelatec ${ }^{\circledR}$, com 6 g 100 litros de solução, e aplicando-se, aproximadamente, $500 \mathrm{~mL}$ em cada planta. O Quelatec ${ }^{\circledR}$ é uma mistura sólida de EDTA-Chelated nutrientes contendo $0,28 \%$ de $\mathrm{Cu}, 5,7 \%$ de $\mathrm{Fe}, 3,5 \%$ de $\mathrm{Mn}, 0,7 \%$ de $\mathrm{Zn}, 0,65 \%$ e B e $0,3 \%$ de Mo.

A semeadura foi realizada colocando-se cinco sementes do cultivar Maxixe do Norte em cada vaso. Cinco dias após a emergência das plântulas, realizou-se o desbaste, deixando-se em cada vaso a plântula mais vigorosa.

No período entre a semeadura e o desbaste, a irrigação foi realizada, utilizando-se água proveniente do sistema de abastecimento do campus da UFERSA $\left(\mathrm{S}_{1}\right)$. No dia seguinte, após o desbaste, a irrigação foi realizada, utilizando-se água com diferentes teores de salinidade, de acordo com os tratamentos delineados.

O suprimento de água para as plantas foi realizado com frequência de uma irrigação diária, até os 30 dias após a semeadura (DAS), e, do $31^{\circ}$ DAS até a colheita, foi adotada a frequência de duas aplicações por dia, uma, pela manhã e, outra, à tarde, de acordo com a necessidade da cultura. Em cada irrigação, foi aplicado volume de água suficiente para elevar a umidade do solo próximo da máxima capacidade de retenção de água de forma que as irrigações eram encerradas quando se observava início de drenagem.

Durante o período experimental, foram realizadas cinco colheitas de frutos, sendo a primeira aos 60 dias após a semeadura, e, as demais, em intervalos semanais. Os frutos colhidos foram contabilizados para determinação do número de frutos por planta (NFR); pesados para determinação da massa média de frutos frescos (MMFR), expressa em grama; e produção de frutos (PROD), expressa em g/planta.

Tabela 1. Características físicas e químicas dos solos utilizados no experimento

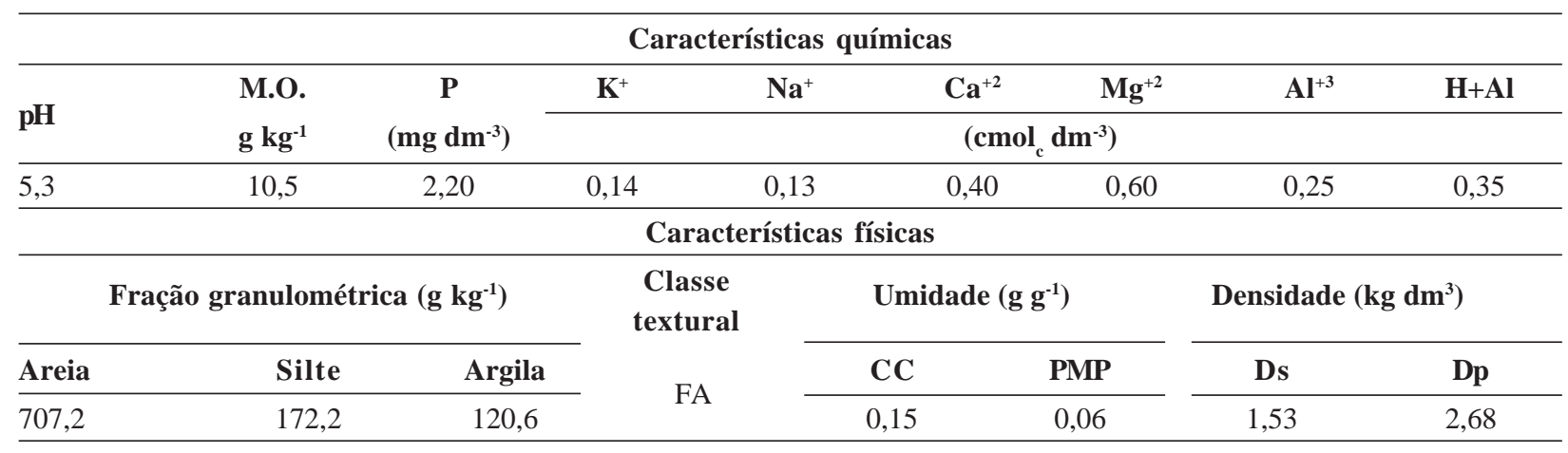

FA - Franco Arenoso; CC - Capacidade de Campo para è = $10 \mathrm{KPa}$; PMP - Ponto de Murcha Permanente para è = 1500KPa; Ds - Densidade do solo ou aparente; DP - Densidade das Partículas. Na determinação do teor de fósforo, foi utilizado o extrator químico Mehlich 1. 
Aos 88 dias após a semeadura, as plantas foram coletadas, analisadas quanto aos seguintes indicadores de desenvolvimento: diâmetro do caule (DC), determinado com paquímetro digital, em mm, comprimento do ramo principal (CRP), determinado com trena, em cm, número de folhas (NF), considerando-se as folhas, maiores que três $\mathrm{cm}$, área foliar (AF), determinada utilizando-se integrador de área (modelo LI-3100 da Licor.), massa seca de haste (MSH), folhas (MSF), frutos (MSFR) e total (MST).

Para determinação da massa seca, as plantas foram fracionadas, acondicionadas em sacos de papel e postas para secar, em estufa de circulação forçada de ar, à temperatura de $70^{\circ} \mathrm{C} \pm 1^{\circ} \mathrm{C}$. Após atingir peso constante, o material seco foi pesado separadamente, utilizando-se balança digital $(0,01 \mathrm{~g})$.

Os dados obtidos foram submetidos à análise de variância e os resultados do efeito da salinidade foram submetidos à análise de regressão.

\section{RESULTADOS E DISCUSSÃO}

$\mathrm{Na}$ Tabela 2, é mostrado o resumo da análise de variância para as variáveis analisadas, na qual se verificou resposta negativa e significativa da cultura do maxixeiro à salinidade da água de irrigação, a 1\% de probabilidade de significância, para todas as variáveis analisadas. Estes resultados reforçam a importância da qualidade da água na irrigação do maxixeiro, semelhantemente aos encontrados por outros autores para outras espécies da mesma família botânica, como o meloeiro (Medeiros et al., 2012), pepineiro (Santana et al., 2010) e a abobrinha (Strassburger et al., 2011).

\section{Desenvolvimento vegetativo}

Para as variáveis comprimento do ramo principal (CRP), diâmetro do caule (DC) e área foliar (AF) verificaram-se respostas lineares e decrescentes, em função do aumento da salinidade da água de irrigação. Houve reduções de 6,6 cm em CRP, 0,39 mm em DC e 69,80 $\mathrm{cm}^{2}$ na AF por planta para cada aumento unitário da condutividade elétrica da água utilizada na irrigação $\left(\mathrm{CE}_{\mathrm{a}}\right)$, sendo obtidos, em todos os casos, os menores valores na $\mathrm{CE}_{\mathrm{a}}$ de 5,0 dS $\mathrm{m}^{-1}\left(51,55 \mathrm{~cm}, 3,63 \mathrm{~mm}\right.$ e $298,65 \mathrm{~cm}^{2}$ por planta respectivamente para CRP, DP e AF) e, os maiores, na $\mathrm{CE}_{\mathrm{a}}$ de $0,5 \mathrm{dS}$ $\mathrm{m}^{-1}\left(81,25 \mathrm{~cm}, 5,37 \mathrm{~mm}\right.$ e $298,65 \mathrm{~cm}^{2}$ por planta respectivamente para CRP, DPe AF). Tais alterações corresponderam a perdas totais de 36,56\% em CPR, 32,50\% em DC e 51,26\% em AF quando se utilizou água com 5,0 dS m ${ }^{-1}$ de CE (Figura 1A, 1B e 1D). Resultados semelhantes foram encontrados por Queiroga et al. (2006), trabalhando com três híbridos de melão, os quais constataram que a irrigação com água salina também provocou redução na altura das plantas, enquanto que Dias et al. (2010), observaram, para essa mesma cultura, efeito depressivo da salinidade sobre o diâmetro do caule.

Na literatura, são escassos os trabalhos que avaliam o efeito da salinidade na cultura do maxixeiro. No entanto, são vários os estudos que relatam o efeito do estresse salino sobre o desenvolvimento foliar de outras culturas da mesma família botânica. Farias et al. (2003) e Porto Filho et al. (2006), trabalhando com a cultura do meloeiro, também observaram efeito negativo da salinidade sobre a AF.

Segundo Tester \& Davenport (2003), a menor área foliar das plantas do meloeiro, para os teores de salinidade mais elevados, reflete o efeito do potencial osmótico da solução do solo, inibindo a absorção de água pela planta, sendo que o decréscimo da área foliar está, possivelmente, relacionado com um dos mecanismos de adaptação da planta ao estresse salino e à diminuição da superfície transpirante.

O número de folhas (NF) também foi afetado pela salinidade da água de irrigação. No entanto, o efeito da salinidade foi menos deletério para essa característica, em

Tabela 2. Resumo da análise de variância para número de folhas (NF), comprimento do ramo principal (CRP), diâmetro do caule (DC), área foliar (AF), massa seca de folhas (MSF), caule (MSC), frutos (MSFR) e total (MST), número de frutos (NFR) e produção do maxixeiro irrigado com águas salinas

\begin{tabular}{|c|c|c|c|}
\hline Variáveis & Quadrados médios & Resíduo & $\mathrm{CV}(\%)$ \\
\hline Número de folhas & $703,28 * *$ & 47,9 & 10,74 \\
\hline Comprimento o ramo principal & $1157,60 * *$ & 60,13 & 11,68 \\
\hline Diâmetro do caule & $3,99 * *$ & 0,13 & 9,79 \\
\hline Área foliar & $113340,17 * *$ & 744,44 & 7,99 \\
\hline Massa seca de folhas & $13,90 * *$ & 0,18 & 7,72 \\
\hline Massa seca de caule & $13,99 * *$ & 0,29 & 14,54 \\
\hline Massa seca de frutos & $253,07 * *$ & 1,11 & 11,46 \\
\hline Massa seca total & $544,84 * *$ & 2,71 & 8,97 \\
\hline Número de frutos & $40,11^{* *}$ & 5,38 & 14,47 \\
\hline Produção & $37625,21^{* *}$ & 334,05 & 8,96 \\
\hline
\end{tabular}

**Significativo a $1 \%$ de probabilidade 
comparação com o efeito em CRP, DC e AF. Inicialmente, foi observada resposta positiva ao grau de salinidade, até $1,54 \mathrm{dS} \mathrm{m}^{-1}$, em que se constataram aproximadamente 73 folhas por planta. A partir desse grau de salinidade, houve decréscimo do NF, apesar de mais acentuado a partir de $3,5 \mathrm{dS} \mathrm{m}^{-1}$. O menor NF ocorreu com o grau de salinidade de 5,0 dS m${ }^{-1}$, com 49 folhas por planta. Comparando-se os valores obtidos nos graus de salinidades de 1,54 e 5,0 $\mathrm{dS} \mathrm{m}{ }^{-1}$, verifica-se redução total de $32,3 \%$ (Figura $1 C$ ).

A ausência de efeito negativo da salinidade até 1,54 $\mathrm{dS} \mathrm{m}{ }^{-1}$ sobre o NF indica, que, provavelmente, esta variável não pode ser usada como um bom parâmetro para indicar tolerância à salinidade (Silva Júnior et al., 2013), uma vez que, apesar de ocorrer pouco efeito sobre a emissão de folhas, poderá ocorrer redução na expansão do limbo foliar, o que provocará possível perda na capacidade fotossintética ativa da planta.

Analisando-se o comportamento do NF e da AF, em conjunto, verifica-se que a emissão de novas folhas é menos sensível à salinidade que a expansão do limbo foliar, indicando que as plantas podem ter utilizado, como estratégia de defesa contra o estresse salino, a redução da área foliar, desenvolvendo folhas menores.
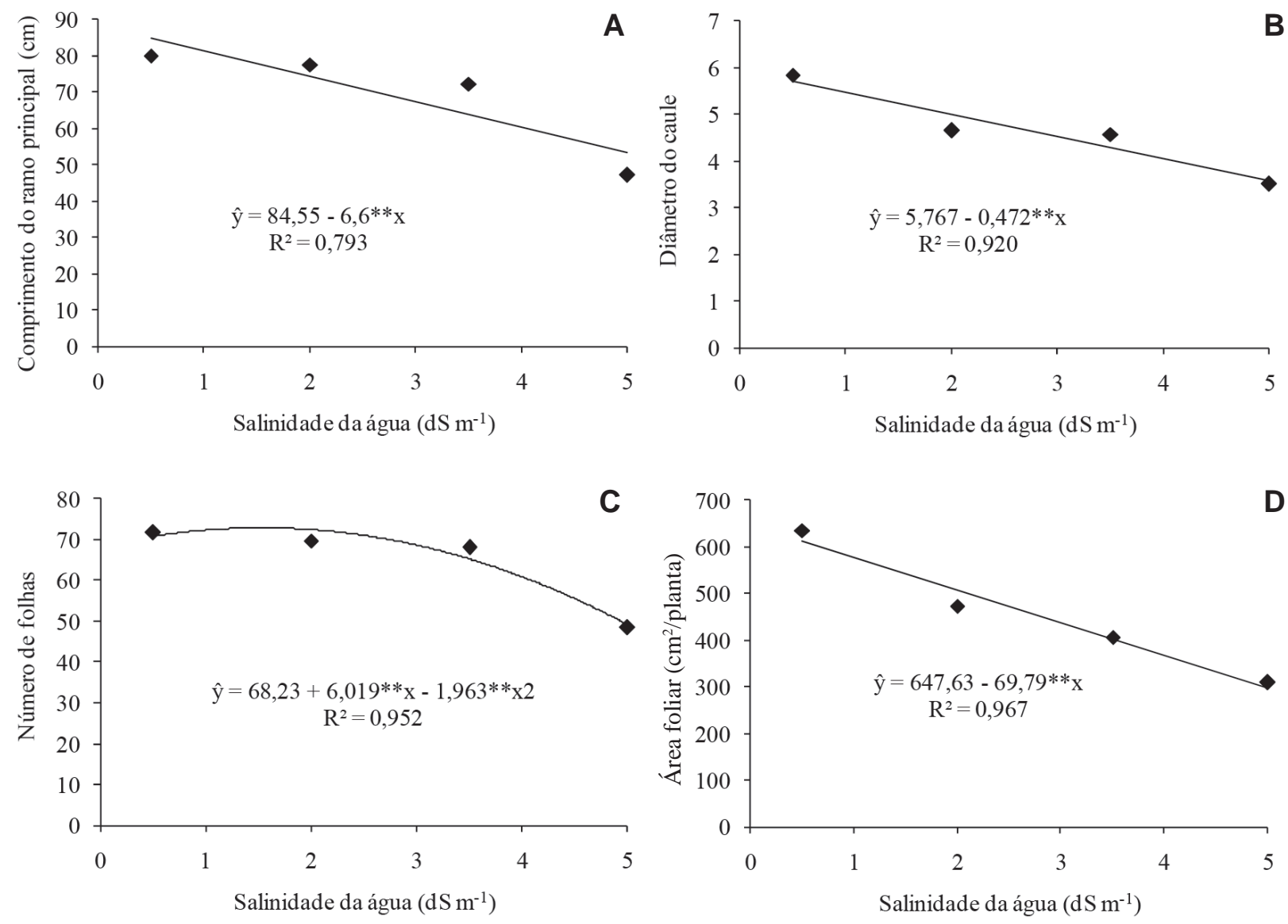

Figura 1. Comprimento do ramo principal (A), diâmetro do caule (B), número de folhas (C) e área foliar (D) do maxixeiro irrigado com águas salinas.

Rev. Ceres, Viçosa, v. 61, n.1, p. 147-154, jan/fev, 2014 
Farias et al. (2003) notaram comportamento similar para o meloeiro, híbrido Gold Mine, quando estudaram dois níveis de salinidade da água de irrigação $(0,55$ e 2,65 dS m $\left.{ }^{1}\right)$ e constataram que o acúmulo de fitomassa seca foi afetado pela crescente salinidade da água.

\section{Rendimento}

Para todos os indicadores de rendimento analisados, foram observadas respostas significativas e negativas, em cada grau de salinidade da água de irrigação. Verificaram-se reduções de aproximadamente 1,29 frutos por planta, $1,62 \mathrm{~g}$ por fruto e $40,62 \mathrm{~g}$ de frutos por planta em resposta ao aumento unitário da condutividade da água de irrigação, que corresponderam a reduções totais de $32,38 \%$ no número de frutos por planta, $43,27 \%$ na massa média de frutos e $61,9 \%$ na produção das plantas irrigadas com água de maior salinidade $\left(5,0 \mathrm{dS} \mathrm{m}^{-1}\right)$. Nessa condição obtiveram-se 12,1 frutos por planta, 9,57 g de massa média frutos e produção de $112,4 \mathrm{~g}$ de frutos por planta. Todas essas variáveis apresentaram valores máximos nas plantas irrigadas com água de menor salinidade $(0,5 \mathrm{dS} \mathrm{m}$ $\left.{ }^{1}\right)$, e que foram de 17,9 frutos por planta, $16,86 \mathrm{~g}$ por fruto e 295,5 g de frutos por planta (Figura 3A, 3B e 3C).
Redução no número de frutos, em resposta ao estresse salino, já foi relatada para outras culturas, como o meloeiro (Medeiros et al., 2012) e o pepineiro (Santana et al., 2010). Outros autores encontraram respostas diferentes da obtida neste trabalho, como Medeiros et al. (2009), trabalhando com a cultura do pepineiro; e Strassburger $e t$ al. (2011), trabalhando com a cultura da abobrinha. Esses autores relataram resposta quadrática para o número de frutos, com o aumento da salinidade; no entanto, vale salientar que obtiveram aumento da salinidade a partir da adição de fertilizantes, o que pode diminuir o efeito da salinidade sobre as plantas.

O efeito negativo do aumento da salinidade sobre a massa fresca de frutos ocorre em consequência da menor absorção de água e, consequentemente, de nutrientes, pelas plantas, tendo em vista que o teor de água em frutos crus de maxixe situa-se em torno de $95,1 \%$ (NEPA, 2011).

Sabe-se que, com o aumento da salinidade da água de irrigação ocorre maior quantidade de sais depositados no solo, o que altera o potencial osmótico, reduzindo o consumo de água pelas plantas e, consequentemente, de nutrientes, diminuindo assim a produção das plantas.
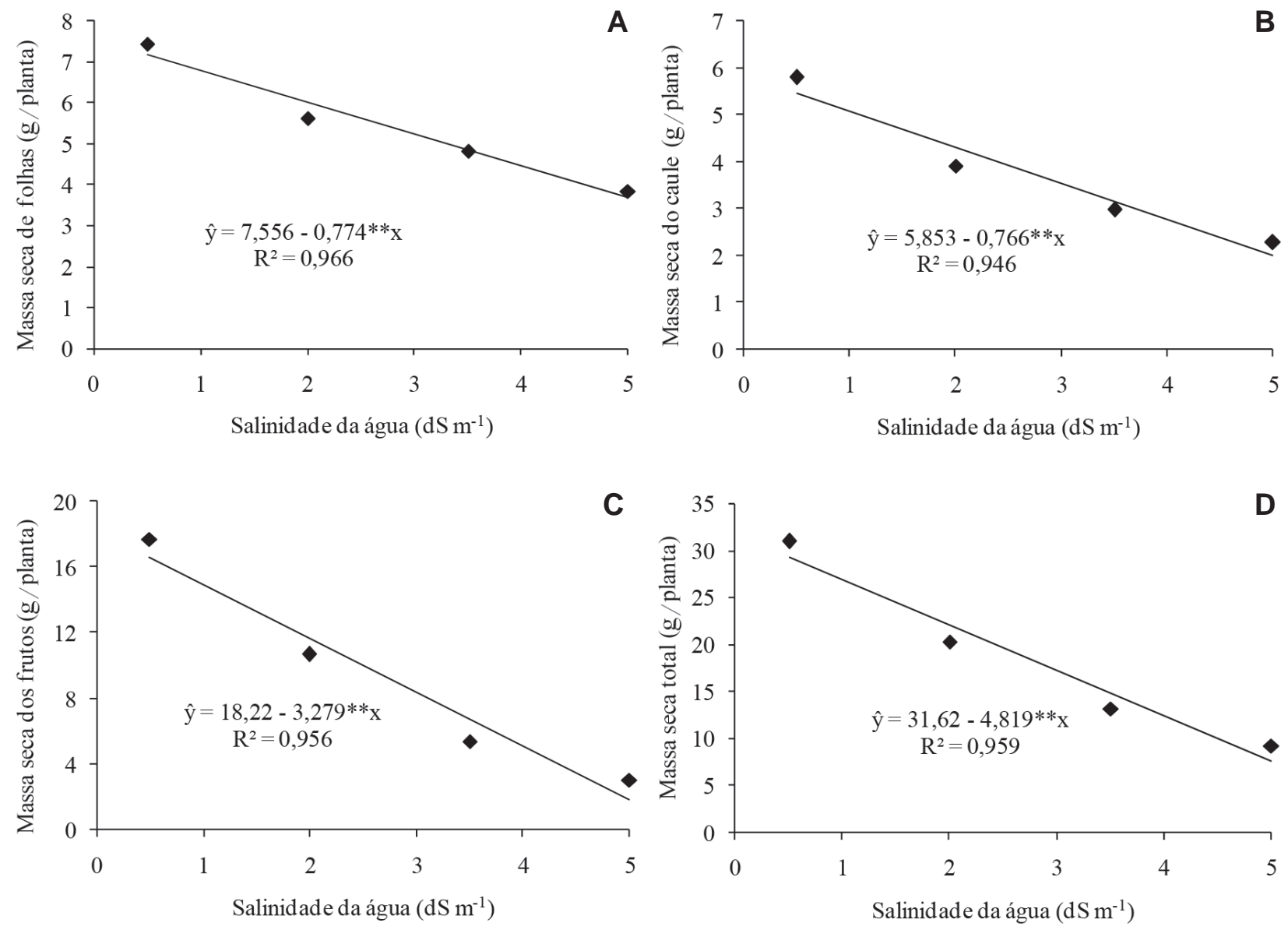

Figura 2. Massa seca de folhas (A), caule (B), frutos (C) e total (D) do maxixeiro irrigado com águas salinas.

Rev. Ceres, Viçosa, v. 61, n.1, p. 147-154, jan/fev, 2014 

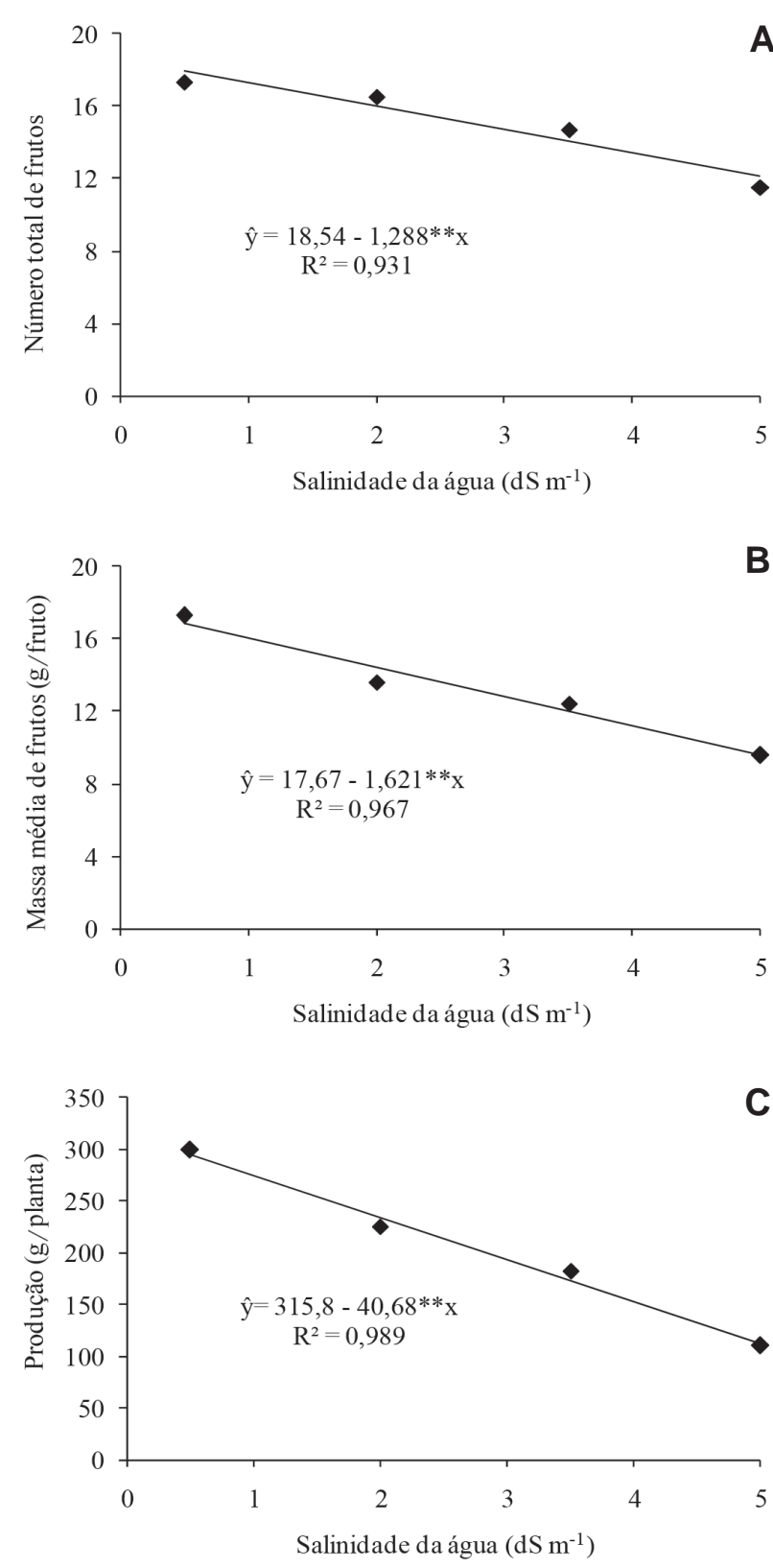

Figura 3. Número de frutos (A), massa média de frutos (B) e produção $(\mathrm{C})$ do maxixeiro irrigado com águas salinas.

Esses resultados, em confronto com os da literatura, demonstram que o maxixeiro está entre as cucurbitáceas sensíveis à salinidade, comparando-se com culturas como abobrinha e melão, que apresentam rendimento potencial de $90 \%$, com salinidade da água utilizada na irrigação de até 2,6 e 2,4 dS m ${ }^{-1}$, respectivamente (Ayers \& Westcot, 1999).

\section{CONCLUSÕES}

O crescimento, produção de massa de matéria seca, número de frutos, massa média de frutos e produtividade do maxixeiro foram reduzidos com o aumento da salinidade da água de irrigação, a partir da condutividade elétrica de $0,5 \mathrm{dS} \mathrm{m}^{-1}$.

\section{A REFERÊNCIAS}

Ayers RS \& Westcot DW (1999) A qualidade da água na agricultura. Campina Grande, UFPB. 218p.

Brasil (2004) Ministério da Saúde. Agência Nacional de Vigilância Sanitária. Consulta Pública n ${ }^{\circ}$. 81, de 13 de dezembro de 2004. Regulamento Técnico para Produtos de Vegetais, Produtos de Frutas e Cogumelos. Diário Oficial da União, de 17 de dezembro de 2004. Disponível em: <http://www.anvisa.gov.br/alimentos/ cp/81_04.pdf>. Acessado em: 15 de janeiro de 2013.

Carmo Filho F \& Oliveira OF (1995) Mossoró: Um município do semiárido nordestino, caracterização climática e aspecto florístico. Mossoró, ESAM. 62p.

Carmo GA, Oliveira FRA, Medeiros JF, Oliveira FA, Campos MS \& Freitas DC (2011) Teores foliares, acúmulo e partição de macronutrientes na cultura da abóbora irrigada com água salina. Revista Brasileira de Engenharia Agrícola e Ambiental, 15:512518.

Casaroli D \& Jong Van Lier Q (2008) Critérios para determinação da capacidade de vaso. Revista Brasileira de Ciência do Solo, 32:59-66.

Dias NS, Lira RB, Brito BL, Sousa Neto ON, Ferreira Neto M \& Oliveira AM (2010) Produção de melão rendilhado em sistema hidropônico com rejeito da dessalinização de água em solução nutritiva. Revista Brasileira de Engenharia Agrícola e Ambiental, $14: 755-761$

Embrapa - Empresa Brasileira de pesquisa Agropecuária (1997) Serviço Nacional de Levantamento e Conservação do Solo. Manual de métodos de análise de solo. 2a ed. Rio de Janeiro, EMBRAPA/SNLCS. 211p.

Farias CHA, Espínola Sobrinho J, Medeiros JF, Costa MC, Nascimento IB \& Silva MC (2003) Crescimento e desenvolvimento da cultura do melão sob diferentes lâminas de irrigação e salinidade da água. Revista Brasileira de Engenharia Agrícola e Ambiental, 7:445-450.

Góis VA, Torres SB \& Pereira RA (2008) Germinação de sementes de maxixe submetidas a estresse salino. Revista Caatinga, 21:6467.

IBGE - Instituto Brasileiro de Geografia e Estatística (2012) POF - Pesquisa de Orçamentos Familiares 2008 - 2009. Disponível em: <http://www. ibge.gov.br>. Acessado em: 05 de junho de 2013.

Maas EV \& Hoffman GJ (1977) Crop salt tolerance - Current Assessment. Journal of Irrigation and Drainage Division, 103:115-134.

Medeiros DC, Medeiros JF, Barbosa MAG, Queiroga RCF, Oliveira FA \& Freitas WES (2012) Crescimento do melão Pele de Sapo, em níveis de salinidade e estágio de desenvolvimento da planta. Revista Brasileira de Engenharia Agrícola e Ambiental, 16:647654.

Medeiros PRF, Duarte SN \& Dias CTS (2009) Tolerância da cultura do pepino à salinidade em ambiente protegido. Revista Brasileira de Engenharia Agrícola e Ambiental, 13:406-410.

Modolo VA \& Costa CP (2003) Maxixe: uma hortaliça de tripla forma de consumo. Piracicaba, DIBD/ESALQ. 24p. (Série Produtor Rural, 19).

Munns R (2005) Genes and salt tolerance: bringing them together. New Phytologist, 167:645-663.

Nascimento AMCB, Nunes RGFL \& Nunes LAPL (2011) Elaboração e avaliação química, biológica e sensorial de conserva de maxixe (Cucumis anguria L.). Revista ACTA Tecnológica, 6:123-136.

Rev. Ceres, Viçosa, v. 61, n.1, p. 147-154, jan/fev, 2014 
Nepa (2011) Núcleo de Estudos e pesquisas em Alimentação. Tabela brasileira de composição de alimentos. $4^{\mathrm{a}}$ ed. Campinas, NEPAUNICAMP. 161p.

Oliveira AP, Oliveira ANP, Alves EU, Alves AU, Leonardo FAP \& Santos RR (2008) Rendimento de maxixe em função de doses de $\mathrm{P}_{2} \mathrm{O}_{5}$ e solo arenoso. Ciência e Agrotecnologia, 32:1203-1208.

Oliveira FA, Oliveira MKT, Lima LA, Bezerra FMS \& Cavalcante ALG (2012) Desenvolvimento inicial do maxixeiro irrigado com águas de diferentes salinidades. Agropecuária Científica no Semi-Árido, 8:22-28.

Porto Filho FQ, Medeiros JF, Gheyi HR, Matos JA, Souza ER \& Sousa Neto ER (2006) Crescimento do meloeiro irrigado com águas de diferentes salinidades. Horticultura Brasileira, 24:334341 .

Queiroga RCF, Andrade Neto RC, Nunes GHS, Medeiros JF \& Araújo WBM (2006) Germinação e crescimento inicial de híbridos de meloeiro em função da salinidade. Horticultura Brasileira, 24:215-319.
Santana MJ, Carvalho JA \& Miguel DS (2010) Respostas de plantas de pepino à salinidade da água de irrigação. Global Science Technology, 3:94-102.

Silva Júnior GS, Silva LE, Aguiar LAA \& Lima AB (2013) Efeito do estresse salino sobre o crescimento e equilíbrio nutricional em cultivares de melão. Revista Cientec, 5:63-77. Strassburger AS, Peil RMN, Fonseca LAF \& Aumonde TZ (2011) Crescimento e produtividade da abobrinha italiana: efeito da concentração iônica da solução nutritiva. Semina - Ciências Agrárias, 32:553-564.

Tester M \& Davenport R (2003) $\mathrm{Na}^{+}$tolerance and $\mathrm{Na}^{+}$transport in higher plants. Annals of Botany, 91:503-527. 